\title{
SILK as Kanji Learning Model for Students at Japanese Department
}

\author{
Amira Agustin Kocimaheni \\ Japanese Department \\ Universitas Negeri Surabaya \\ Surabaya, Indonesia \\ amiraagustin@unesa.ac.id
}

\begin{abstract}
Japanese language learners at the university level must master the knowledge of Japanese letters, which consists of kana and kanji. There are no difficulties for the students who have already been familiar with Japanese letters to know the characteristics of kana and kanji. On the contrary, students who have no background of studying Japanese will think that writing and reading Japanese letters is a challenging effort. Therefore, a learning model which introduces the strategies of Japanese letters, especially kanji, is necessary for the beginner. This paper aims at proposing a learning model which is integrated with the courses of Shokyu Hyoki. The learning model introduces learning strategies in learning kanji which is appropriate with the students' needs and characteristics. The goal is to make the students know kanji learning strategies based on Strategy Inventory for Learning Kanji (SILK). In the end, the students will be able to decide and use the appropriate kanji learning strategy for them.
\end{abstract}

Keywords- kanji, Strategy Inventory for Learning Kanji (SILK), learning model, learning

\section{INTRODUCTION}

Japanese language has three kinds of letters namely hiragana, katakana and kanji. The students who are learning Japanese language must know those kinds of letters, especially kanji. Kanji has certain characteristics, for example the number of strokes (kakijun), Japanese ways of reading (kunyomi), Chinese ways of reading (onyomi), combination of several kanji (jukugo), radical marker (bushu) and sound marker (onkigo).

Kanji has much more letters than hiragana and katakana. Hiragana and katakana each has 46 letters and they are in the form of meaningless syllables whereas, in kanji, each letter has their own meaning. There are more or less 50.000 kanji characters. In 1981 Japanese government introduces a list of kanji letters known as Joyokanji List. It has 1945 kanji characters. The list serves as a guidance for the foreigners to learn kanji to make able to communicate using the list of the kanji letters. Due to the need of the society, such as for the Japanese Language Proficiency Test (JLPT) at the highest level, level 1. Level 1 JLPT requires kanji mastery in more or less 2000 characters, therefore in 2010 , the revised Joyokanji List there are 2136 characters.
TABLE I. The DifFERENCES OF KANJI, HiRAGANA, KATAKANA AND ROMAJI/ALFABET

\begin{tabular}{|c|l|l|c|c|}
\hline Kanji & Hiragana & Katakana & Romaji & English \\
\hline 私 & わたし & ワタシ & watashi & I, me \\
\hline 愛 & あい & アイ & ai & love \\
\hline 山 & やま & ヤマ & yama & mountain \\
\hline 東京 & とうきょう & トウキョウ & tokyo & Tokyo \\
\hline
\end{tabular}

Source: http://gjworks.net/tsl/en/images/japanesewritingsystem.jpg

There are several important points in learning kanji, namely the number of strokes, the sequence of strokes, the pattern, bushu (the radical marker) and the onpu as in [5].

The Indonesian students who are learning kanji can be included as the students who do not have any previous background of learning kanji (hikanjiken). They have to learn and memorise the characteristic of kanji letters which are different from the character of the common alphabet that they know. One of the characteristics of kanji, for example kanji

「日」 (sun, day) can be read in many different ways. It can be read 'hi' in the word「日焼け」'hiyake' (sunburn); 'bi' in the word 「月曜日」'getsuyoubi' (Monday); 'ka' in the word 「二日」'futsuka' (second day of the month/two days); 'nichi' in the word「日用」 'nichiyou' (daily use); 'jitsu' in the word 「本日」 'honjitsu' (today). It can also be read as a specific kanji in the word 「今日」 'kyou' (today); in the word 「昨日」 'kinou' (yesterday) and in the word 「明日」 'ashita/asu' (tomorrow).

Beside the ways in reading the letters, there are some kanji letters which have different meaning even though they are the same kanji letters. For example, in the word「二日」'futsuka' (second day of the month/two days). There is also the same kanji but different in the ways of reading, such as in the word

「明日」 read as 'ashita/asu' (tomorrow).

Kanji has a stroke order in which students must know and master it. For example, in kanji 「人」 'jin' (person) and kanji 
「入」 'hairu' (enter). They look similar, but we can see the stroke order for both kanji letters in the following figure.

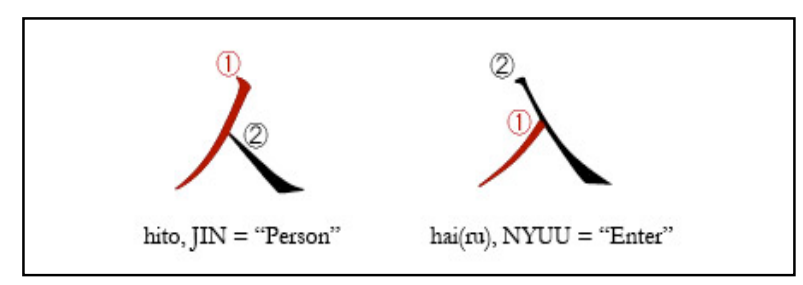

Fig. 1. Stroke order Kanji 人 dan 入

Source:http://nihonshock.com/2009/09/20-similar-looking-kanji

Another difficulty is related with the number of kanji letters. Therefore the students need to know how to master kanji. Each learner has their own characteristics and strategy to learn and master kanji. That is, judging from the problems explained previously, this paper aims to propose the use of strategy named SILK (Strategy Inventory for Learning Kanji developed by Barbara Bourke in 2006.

\section{KANJI LEARNING STRATEGY}

In the effort to master something, it takes a strategy or certain ways as a part of learning processes and stages. Oxford [6] states that learning strategy is a procedure used by the students or teacher to ease the learning process, especially for acquiring knowledge, accumulation, and the use of the acquired knowledge.

Learning strategy can also be applied in learning kanji. Gamage [4] also describes three important factors in applying strategy to learn kanji namely:

a) The level of the language learner will influence the learning strategy used to teach kanji. This is related with the preferences of the learning strategy used in learning a certain language.

b) The decision and the choosing of the learning strategy is connected with the cognitive and linguistic transfer from the native language to the target language.

The decision of the generalisation is gotten by identifying the strategies which are unique and have specific characteristics, for example memorizing a lot of reading passages when learning new kanji letters.

\section{AUTONOMOUS LEARNER THEORY}

The fact that there are so many numbers of kanji with its characteristics which must be learnt and memorized, the students are highly suggested to learn how to become autonomous learners. If they only learn from the classroom they will not have enough time to learn. Autonomous learner is students involved in decision making processes regarding their own language competence as in [1]. Deyun \& Longmin, [3] mentions crucial factors to the development of teacher autonomoy: learner choice, voluntariness, flexibility, teacher instruction.

\section{STRATEGY INVENTORY FOR LEARNING KANJI (SILK)}

Strategy Inventory for Learning Kanji (SILK) is an instrument which was developed by Barbara Bourke, a lecturer at the Queensland University in 2006. SILK is designed with the purpose of gathering information on the strategy used by the Japanese language learners in learning kanji. The standardized identification on ways of learning kanji in SILK is divided into 15 points:
a. Association,
b. Stories,
c. Bushu (Radicals),
d. Frequency,
e. Experience,
f. Visualisation,
g. Self-monitoring,
h. Compensation,
i. Sequence,
j. Physical/Emotional Response,
k. Sound,
1. Stroke Order,
m. Planning Your Learning,
n. Evaluating Your Learning, and
o. Cooperating With Others.

The following is the description of the strategy in learning kanji according to Bourke.

\section{a) Association}

Association in this sense is the learner's effort to learn kanji by associating the previous kanji they have learned, such as katakana, the alphabets or other symbols. They can also associate it with kanji from the same group with the same meaning or kanji with the opposite meaning, or kanji with the same ways of reading but has different meaning, or it can be similar kanji but different meaning. All of those strategies are related with connecting or associating new knowledge and the previous knowledge which can lead to effective learning.

\section{b) Stories}

It is a strategy to develop a certain story about kanji. The story can be about the elements of kanji character, the meaning from the bushu (radical) in kanji, or other factors which can give meaning to the learned kanji to the learner. 


\section{c) Bushu (Radicals)}

It is one of the ways to classify kanji based on several elements which can be found in kanji. By using bushu as a strategy, it means that knowing the meaning from bushu and connect the meaning with meaning from kanji as a whole.

\section{d) Frequency}

It is a memorizing kanji strategy by writing kanji over and over again or memorize it by using it intensively.

\section{e) Experience}

It is a strategy which connects the meaning of the kanji with a personal experience which can make the learner remembers the experience and then connect it with the kanji.

\section{f) Visualisation}

The learner can visualize the kanji in his/her mind before writing it down on a piece of paper or when the learner can precisely remembers on what page where the kanji is written and the form on that page. It is almost like a photographic memory.

\section{g) Self-monitoring}

Self-monitoring refers to a general self-evaluation test, a conscious reflection on the mistakes with the attention not to make the same mistakes again and the use of tools or materials which can help to remember the difficult or confusing kanji.

\section{h) Compensation}

It is a strategy of using other means when our knowledge is insufficient. For example, by asking other learners, teacher, dictionary, or a text book. Compensation can be categorized as a positive strategy because in the end the learner can absorb the knowledge which he/she has not acquired yet, especially if the leaner can make the list of the knowledge.

\section{i) Sequence}

This strategy is related with remembering kanji in the context of a word or a sentence. For a certain learner, this strategy might not work directly if the kanji stands alone, but if it is in the form a word or a sentence the memory can be recalled.

\section{j) Physical/Emotional Response}

Sometimes learner can remember kanji through ways which is very personal, such as a learner remembers kanji 弟('otouto', little brother) easily because he/she just has got a little brother. It can also because the kanji is very difficult to be written or other reasons.

\section{k) Sound}

Remembering kanji through how the kanji is pronounce in Bahasa Indonesia (the learner's native language), or through on or kun reading ways can become the trigger the memory to recall the kanji.

\section{l) Stroke Order}

By knowing which stroke that has to be written first will help the learner remembers the order of writing the next kanji. The stroke order is related with a certain rhyme, pattern, and context which kanji is formed. By writing kanji carefully and repeatedly with the correct order can be used as a strategy to remember on how to write kanji.

\section{m)Planning Your Learning}

Learning will not be successful if the learner does not allocate special time in learning the subject. Planning learning is related with setting a specific amount time every week to learn kanji and decide on the appropriate and effective method in doing the task. The learner needs to choose the appropriate method that suits their learning style and make use of the time effectively.

\section{n) Evaluating Your Learning}

This strategy is related with self-monitoring strategy, but the emphasis is more to the process learning kanji as a whole. One of the ways is by writing a diary as a means to record the improvement of learning kanji. By writing a diary the learner can also understand his/her learning pattern.

\section{o) Cooperating with Others}

Learning other learners gives advantages of sharing the strategy in learning kanji and ways to remember it. By learning with others, the learner aware that he other learner also face difficulty in learning kanji and has a different strategy in learning kanji.

\section{THE CONCEPTUAL FRAMEWORK OF SILK}

The conceptual framework of the application of SILK follows a series of steps. The first step is the teacher introduces SILK to his students. In this step the teacher can introduce SILK through a presentation or use the SILK website (kanjisilk.net) if possible. The use of the SILK website must be supported by the availability of good internet connection.

The second step deals with training the students on how to use SILK. The teacher forms a team of two students which will enable the students to help each other and to check the use of the strategy when they learn kanji. By doing a pair work, each team has to try to know all strategies in SILK and try to use them. The teacher can move around the class and help the team which faces difficulties in the process of applying SILK.

The third step is based on the previous exercise which has been done. The teacher can already decide that the students are successful in choosing and applying SILK for their learning process. The process of choosing and applying the strategy is actually students' freedom. This process can be done up to the mid-semester or before the mid-term test.

The fourth step is done along with other steps. The teacher can observe and interview the students during their classroom learning activities. The observation and interview instruments can be prepared to be used in the classroom. If the numbers of the students are big, the teacher can ask for assistance from another observer. To support the result of the observation and interview, the researcher can use triangulation with the result of the mid-term test. As the last step, the teacher can do reflection toward the result of the observation, interview, and mid-term test result. 
The application of SILK in the classroom can be continued up to the rest of the semester, and it will be stored in the students' memory for the following semesters. Therefore, the students are expected to be able to choose the strategies in learning kanji which are appropriate with them in the next level of learning kanji.

\section{CONCLUSION}

As a material or a subject that has to be mastered by a student who learn Japanese language, kanji becomes the most unpopular subject to be learned. The number and the characteristics of kanji that contribute to the difficulties for the students to learn it. SILK with its 15 standardized identification can help the students become autonomous learners. Hopefully the teacher can adopt the application of SILK in the teaching of kanji and do researches dealing with the influence of the use of kanji in learning kanji.

\section{ACKNOWLEDGMENT}

The writer would like to express her gratitude to the Japanese Department of Unesa. She also appreciates her colleagues for their precious insights.

\section{REFERENCES}

[1] Balçıkanlı, Cem. Learner Autonomy In Language Learning: Student Teachers' Beliefs. 2010

[2] Bourke, B. Strategy Inventory for Learning Kanji: Test Instrument for Identifying Strategies in Use for Learning Kanji. Brisbane: Queensland University of Technology Press, 2006.

[3] Deyun, S. \& Longmin, P. Promoting Student Autonomy in the Learning of College English. Chongqing University, 2000.

[4] Gamage, G. H.. Issues in Strategy Classifications in Language Learning: A Framework for Kanji Learning Strategy Research, 2003. Accessed from http://ro.uow.edu.au/cgi/viewcontent.cgi?article=1069\&context=artspap ers, 31 July 2017

[5] Kida Mari, et.al.. Moji-Goi wo Oshieru. Tokyo: The Japan Foundation, 2011.

[6] Oxford, R. L. Language Learning Styles and Strategies: An Overview. 2003. Accessed from http://web.ntpu.edu.tw/ language/workshop/read2.pdf, 27 July 2017 